\title{
A PHOTOSYSTEM I MUTANT IN BARLEY (HORDEUM VULGARE L.)
}

by

\author{
BIRGER LINDBERG MØLLER, ROBERT M. SMILLIE' \\ and GUNILLA HØYER-HANSEN
}

Department of Physiology, Carlsberg Laboratory

Gamle Carlsberg Vej 10, DK-2500 Copenhagen Valby

and

IPlant Physiology Unit, CSIRO Division of Food Research and School of Biological Sciences, Macquarie University

P. O. Box 52, North Ryde 2113, Sydney, Australia

Keywords: viridis- $n^{34}$, photochemical activities, P700, thylakoid polypeptides, SDS-

The nuclear gene mutant viridis $-n^{34}$ in barley has been characterized as a photosystem I mutant. The slow component of the light dependent absorption change at $518 \mathrm{~nm}$ and the photooxidation of cytochrome $f$ were greatly reduced in mutant leaves compared with wild-type leaves. The oxidation of cytochrome $f$ in mutant leaves irradiated with far-red light was only $7 \%$ of the value obtained with wild-type. The fast component of the $518 \mathrm{~nm}$ absorbance change was similar in wild-type and mutant leaves. The rate of photosystem I electron transport in the mutant is approximately $10 \%$ of the rate observed with wild-type thylakoids whereas photosystem II electron transport appears normal. Little or no P700 was detected in the mutant. The levels of cytochromes and ferredoxin-NADP ${ }^{+}$oxidoreductase were normal. Mutant thylakoids were unable to generate a proton gradient upon illumination. Analysis of the polypeptide composition of thylakoids of viridis $-n^{34}$ revealed that these are depleted in chlorophyll $a$-protein 1 and three polypeptides believed to be iron-sulfur proteins. These four polypeptides are components of photosystem I particles isolated from wild-type barley.

\footnotetext{
Abbreviations: $\mathrm{Asc}=$ ascorbic acid, $\mathrm{Chl}=$ chlorophyll, $\mathrm{Cyt}=$ cytochrome, $\mathrm{DBMIB}=$ dibromothymoquinone, $\mathrm{DCIP}=2$,6-dichlorophenolindophenol, $\mathrm{DCMU}=3$-13,4-dichlorophenyl)-1,1-dimethylurea, $\mathrm{DTT}=$ dithiothreitol, $\mathrm{FeCN}=$ potassium ferricyanide, $\mathrm{GD}=$ Gramicidin $\mathrm{D}, \mathrm{MeV}=$ methylviologen, $\mathrm{NADP}^{+}=\beta-$ nicotinamide adenine dinucleotide phosphate, $\mathrm{PD}=p$-phenylenediamine, $\mathrm{PS}=$ photosystem, SDS-PAGE $=$ sodium dodecyl sulfate polyacrylamide gel electrophoresis, TMPD $=\mathrm{N}, \mathrm{N}, \mathrm{N}^{\prime}, \mathrm{N}^{\prime}$-tetramethylphenylenediamine, Tricine $=\mathrm{N}$-(tris-(hydroxymethyl)-methyl)glycine, Tris $=$ tris-(hydroxymethyl)aminomethane .
} 


\section{INTRODUCTION}

The identification of barley thylakoid polypeptides with respect to their function can be approached in various ways. Recently, the five different subunits of coupling factor $\left(\mathrm{CF}_{1}\right)$ were identified in the SDS-PAGE electrophoretogram of total barley polypeptides by the use of antibodies raised against purified $\mathrm{CF}_{1}$ and crossed immunoelectrophoresis (22). A different approach is based on comparison of the electrophoretogram of wild-type thylakoid polypeptides with those of mutants with known photosynthetic lesions (28). Photosynthetic mutants available from higher plants have generally been selected due to alterations in their pigment content (13, $17,30,36,37)$. These changes in pigment content are often associated with gross changes in polypeptide composition $(36,37)$. Most of the higher plant photosynthetic mutants available are therefore pleiotropic and the absence of a particular polypeptide band cannot be correlated directly with a measured photosynthetic deficiency. However, screening of a large number of pigment deficient mutants (47) procured a few with almost normal pigment content and with only few changes in their thylakoid polypeptide patterns. One such mutant, viridis $-n^{34}$, was found to be preferentially depleted in chlorophyll $a$-protein 1 and to contain very low amounts of three low molecular weight polypeptides. The mutant has been characterized by measurements of electron transfer reactions, $518 \mathrm{~nm}$ absorption changes, $P 700$, cytochromes, and by the ability of its chloroplasts to establish a proton gradient upon illumination. From the data here presented and from the characterization of photosystem I particles $(37,48)$ it is concluded that the polypeptides missing in viridis $-n^{34}$ are related to photosystem $I$ and that electron transfer in viridis $-n^{34}$ is blocked at $P 700$.

\section{MATERIALS AND METHODS}

\subsection{Plant Material}

The recessive nuclear gene mutant viridis $-n^{34}$ was obtained after treatment of wild-type barley seeds (Hordeum vulgare L. cv. Svalöfs Bonus) with an acute dose of X-rays (15,000 rad) (47). Seeds were germinated in tap water moistened vermiculite and seedlings harvested after growing 7 days at $20^{\circ} \mathrm{C}$ in continuous white light
(1700 lux). Because the mutant is a seedling lethal, stocks are maintained in the heterozygous state. The mutant seedlings are separated from the wild-type phenotype by their slightly paler green color. Because the differences in pigment content between the wild-type and mutants were small, the visually selected mutant seedlings are occasionally contaminated with wild-type plants. However, mutant seedlings exhibit a higher chlorophyll fluorescence than wild-type when illuminated with low intensity UV light and examined through red perspex filters. The visually selected seedlings were therefore checked for the presence of low fluorescing leaves and this ensured reasonably pure samples of mutant leaves.

\subsection{Isolation of chloroplasts}

Chloroplasts to be used in photochemical reactions were prepared by homogenizing precooled leaves in a medium consisting of $0.4 \mathrm{M}$ sucrose, $0.1 \mathrm{~m}$-Tricine, $3 \mathrm{~mm}$-calcium nitrate, and $0.5 \%$ bovine serum albumin, $\mathrm{pH}$ 7.9. For homogenization, a blender fitted with replaceable razor blades was used. The homogenate was filtered through two layers of $31 \mu \mathrm{m}$ nylon gauze and centrifuged $5 \mathrm{~min}$ at $3,000 \mathrm{~g}$. The pellet was resuspended in the same medium, and the homogenate re-centrifuged. The resulting chloroplast pellet was resuspended in $50 \mathrm{~mm}$-sodium chloride, $50 \mathrm{~mm}$-sodium dihydrogenphosphate, $\mathrm{pH} 7.5$, and used for photochemical experiments after dilution with the same buffer to appropriate chlorophyll concentrations. All operations were carried out at $4{ }^{\circ} \mathrm{C}$.

\subsection{Isolation of purified thylakoids}

Thylakoids for electrophoretic analysis were purified by flotation in a discontinuous gradient as described earlier (23). When not immediately used, the preparation was divided into small aliquots to which solid DTT was added. The aliquots were then frozen by immersion into liquid nitrogen and stored at $-20^{\circ} \mathrm{C}$.

\subsection{Sodium dodecyl sulfate polyacrylamide gel electrophoresis (SDS-PAGE)}

SDS-PAGE was performed according to the procedure in (10). Calculation of apparent 
molecular weights corresponding to the polypeptide bands observed were based on the electrophoretic mobilities of protein standards. In addition to the standards employed in (22), the following low molecular weight standards were used: myoglobin (16,900), lysozyme $(14,000)$, ribonuclease $(12,600)$, and cytochrome $c$ $(12,400)$. The electrophoretic behaviour of the low molecular weight standards showed that molecular weight determination in the range below 18,000 becomes highly inaccurate with the gel types used in this study. Molecular weights assigned to polypeptide bands in this range are therefore only given as a guide.

\subsection{Spectrophotochemical measurements}

Photochemical activities of chloroplasts at $23{ }^{\circ} \mathrm{C}$ were measured with an Aminco DW-2a spectrophotometer operated in either the dual wavelength or split beam mode. Where indicated, side illumination was provided perpendicular to the measuring beam by a tungsten-halogen lamp and filtered through a Schott BG- 18 heat filter and appropriate cut-off filters. The light intensity was controlled by use of a rheostat. All measurements were, if not specifically indicated, carried out at saturating light intensities. The activities were calculated from the linear rates observed after any initial transients.

\subsubsection{Photoreduction of ferricyanide (38)}

The assay mixture $(1.5 \mathrm{ml})$ was composed of chloroplasts $\left(4 \mu \mathrm{g}\right.$ chlorophyll $\left.\cdot \mathrm{ml}^{-1}\right), 40 \mathrm{~mm}$ $\mathrm{KH}_{2} \mathrm{PO}_{4}, \mathrm{pH} 7.5,40 \mathrm{~mm}-\mathrm{NaCl}$, and $0.34 \mathrm{~mm}-$ potassium ferricyanide. Where indicated, one or more of the following compounds were included in the assay mixture. Gramicidin D $(2 \mu \mathrm{M}), p$ phenylenediamine $(0.1 \mathrm{mM})$, DBMIB $(1 \mu \mathrm{M})$, and DCMU $(6.7 \mu \mathrm{M})$. The chloroplasts were irradiated from the side with light passed through a red Corning CS2-58 (2403) glass filter and the photomultiplier was protected by a blue-green Corning CS4-96 (9782) glass filter. The spectrophotometer was operated in the dual wavelength mode and the photoreduction of ferricyanide measured as the decrease in absorbance at $420 \mathrm{~nm}$ with the reference wave-length at 450 $\mathrm{nm}$.

\subsubsection{Photoreduction of NADP+ (39)}

The photoreduction of NADP + using water as electron donor was measured in assay mixtures $(1.5 \mathrm{ml})$ composed of chloroplasts $(4 \mu \mathrm{g}$ chlorophyll $\cdot \mathrm{ml}^{-1}$ ), $40 \mathrm{~mm}-\mathrm{KH}_{2} \mathrm{PO}_{4}, \mathrm{pH} 7.5,40$ $\mathrm{mm}-\mathrm{NaCl}, 0.67 \mathrm{~mm}-\mathrm{NADP}{ }^{+}$, gramicidin $\mathrm{D}(2$ $\mu \mathrm{M})$, and an excess of barley ferredoxin and ferredoxin-NADP + oxidoreductase (7). When photoreduction of NADP ${ }^{+}$via photosystem I alone was measured, ascorbate $(2.5 \mathrm{~mm})$ and DCIP $(63 \mu \mathrm{M})$ were added to the reaction mixture. The illumination from the side was passed through a Corning CS2-64 (2030) cut-off glass filter and the photomultiplier protected by a Corning CS7-60 (5840) blue-green filter. The spectrophotometer was operated in the dual wave-length mode and the reduction of NADP + measured as the increase in absorbance at 350 $\mathrm{nm}$ with $370 \mathrm{~nm}$ as the reference wave-length.

\subsubsection{Ferredoxin-NADP+ oxidoreductase}

Ferredoxin-NADP + oxidoreductase activity was measured in the reverse direction using NADPH as the electron donor and DCIP as the electron acceptor. The reaction mixture was composed of chloroplasts ( $4 \mu \mathrm{g}$ chlorophyll $\cdot \mathrm{ml}^{-1}$ ), $40 \mathrm{~mm}-\mathrm{KH}_{2} \mathrm{PO}_{4}, \mathrm{pH} 7.5,40 \mathrm{~mm}-\mathrm{NaCl}, 0.25$ mM-NADPH, and $42 \mu \mathrm{m}-\mathrm{DCIP}$. The reduction of DCIP was monitored by operating the spectrophotometer in the dual wave-length mode and measuring the decrease in absorption at 575 $\mathrm{nm}$ with $540 \mathrm{~nm}$ as the reference wave-length. To compensate for the slow non-enzymatic reaction between NADPH and DCIP, a control experiment with no chloroplasts was carried out and the rate observed in this experiment was subtracted from the above measured rates.

\subsubsection{Light-dependent absorbance change at 518 $n m(41)$}

The light dependent absorbance change at 518 $\mathrm{nm}$ was measured on segments of the primary leaf excised between 1.5 and $2.5 \mathrm{~cm}$ from the top of the leaf. The leaf segment was positioned with its adaxial surface at an angle of $45^{\circ}$ to the light beams. The spectrophotometer was operated in the dual wave-length mode with the measuring beam set at $518 \mathrm{~nm}$ and the reference beam at $540 \mathrm{~nm}$. Cross-illumination with red-light was carried out by filtering the actinic light through either a Corning CS2-60 (2408) cut-off filter, or 
through the same Corning filter combined with either a $710 \mathrm{~nm}$ interference filter or a $641 \mathrm{~nm}$ interference filter (Bausch and Lomb). The respective light intensities obtained at these three experimental conditions were $72,2.8$, and 4.6 watts $\cdot \mathrm{m}^{-2}$

\subsubsection{Photooxidation of cytochrome $f$ (cytochrome-554)}

The photooxidation of cytochrome $f$ upon illumination of a segment of an intact leaf was measured as described previously (39). The spectrophotometer was operated in the dual wave-length mode and the changes upon illumination of the absorbance at $554 \mathrm{~nm}$ and $541 \mathrm{~nm}$ were measured (2). Otherwise, conditions were as described in section 2.5.4.

\subsubsection{Cytochromes}

Quantitative determination of the content of cytochromes $f, b_{559}$, and $b_{6}$ in isolated chloroplasts was carried out by reduced minus oxidized difference spectroscopy (15). Ferricyanide was used as the chemical oxidant, sodium dithionite and hydroquinone as chemical reductants.

\subsubsection{Proton gradient formation (9)}

Determination of the light dependent generation of a proton gradient was carried out in an assay mixture $(1.5 \mathrm{ml})$ composed of chloroplasts (40 $\mu$ g chlorophyll $\left.\cdot \mathrm{ml}^{-1}\right), 0.5 \mathrm{~mm}-$ Tricine $(\mathrm{pH}$ $8.0), 30 \mathrm{~mm}-\mathrm{NaCl}, 4 \mathrm{~mm}-\mathrm{MgCl}_{2}, 0.2 \mathrm{~mm}-$ methyl viologen, $30 \mu \mathrm{M}$-phenol red, and $2 \mathrm{~mm}-$ $\mathrm{NaN}_{3}$. Actinic light was passed through a Corning CS2-60 (2408) red cut-off glass filter and the photomultiplier tube protected by a Corning CS4-96 (9782) filter. An increase in the $\mathrm{pH}$ of the medium following illumination results in a change in the color of the $\mathrm{pH}$ indicator phenol red and was measured by operating the spectrophotometer in the dual wave-length mode with the measuring beam set at $548 \mathrm{~nm}$ and the reference beam at $592 \mathrm{~nm}$. Each individual reaction mixture was calibrated by adding 0.20 requivalent of $\mathrm{NaOH}$ and measuring the $\triangle \mathrm{pH}$.

\subsection{8. $P 700$}

$P 700$ was measured from the ferricyanide oxidized minus ascorbate reduced difference spectrum of chloroplasts dispersed in a Triton $\mathrm{X}-100$ containing buffer (21). The duplicate cuvettes contained the following assay mixture $(2.6 \mathrm{ml})$ : chloroplasts $(400 \mu \mathrm{g}$ chlorophyll), Triton X-100 (22.0 mg) and $42 \mathrm{~mm}$-Tricine, $\mathrm{pH}$ 8.0. The spectrophotometer was operated in the split beam mode and the two cuvettes were measured against each other from 640 to 730 $\mathrm{nm}$ to establish a baseline. Ferricyanide was then added to the measuring cuvette to a final concentration of $13 \mathrm{~mm}$ and sodium ascorbate to the reference cuvette to produce a $26 \mathrm{~mm}$ solution. The two cuvettes were then equilibrated for $8 \mathrm{~min}$ before the difference spectrum was recorded. A millimolar extinction coefficient of 64 mequivalents ${ }^{-1} \cdot \mathrm{cm}^{-1}$ was used to convert the observed change in absorbance at 696 minus that at $715 \mathrm{~nm}$ into concentration of $P 700$ (21).

\subsection{Oxygen electrode measurements}

Photosynthetic oxygen evolution associated with photosystem II electron transfer was measured by use of an oxygen electrode (Rank Bros., Bottisham, Cambridge, U.K.) (15). Photosystem I was assayed using ascorbate plus TMPD as the donor system and methyl viologen as the acceptor. The reduced methyl viologen formed reacts chemically with oxygen and the reaction can therefore be followed by measuring oxygen consumption (15).

\subsection{Isolation of ferredoxin and plastocyanin}

Ferredoxin and plastocyanin were isolated from seedlings of barley $(6 \mathrm{~kg})$ essentially by adoption of the methods described for the isolation of the same proteins from spinach (7, 25).

\subsection{Other assays}

Chlorophyll was determined spectrophotometrically in $80 \%$ acetone extracts clarified by centrifugation (1). Protein concentration was measured by the method of Lowry et al. (27) with bovine serum albumin as a standard.

\section{RESULTS}

The recessive nuclear gene mutant viridis $-n^{34}$ in barley was obtained by X-ray treatment of the barley variety Bonus (Svalöf). The lethal mutant 


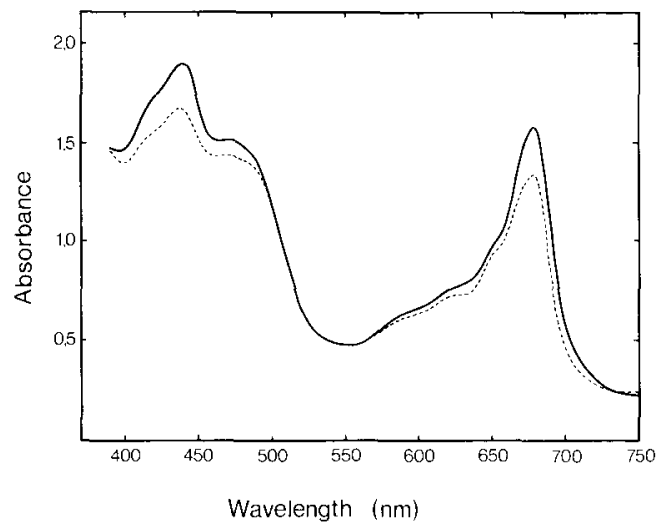

Figure 1. Absorption spectra of intact primary leaves of wild-type barley (-) and the mutant viridis $-n^{34}$ (--).

seedlings grown at $20^{\circ} \mathrm{C}$ are green but can be distinguished visually from the phenotype of the mother variety as being slightly paler. Because the mutant leaves lack the characteristic specks of increased chlorophyll content observed in wild-type leaves, they also appear more uniform in color. For quantitative information on the pigment content of leaves from viridis $-n^{34}$ as compared to wild-type, their in vivo absorption spectra were recorded (Figure 1). As judged from the lower absorption at the red absorption maximum of chlorophyll, the chlorophyll content of viridis- $n^{34}$ leaves reaches $80 \%$ of that of wild-type. The ratio of chlorophyll $a$ to chlorophyll $b$ was 2.8 for viridis $-n^{34}$ as compared to 3.4 for wild-type. The ultrastructure of the mutant chloroplast membranes as analyzed by thin-sectioning and freeze fracturing appears normal (49).

Investigation by SDS-PAGE of the polypeptide patterns of purified thylakoids from viridis$n^{34}$ and wild-type, showed that the mutant was deficient in $P 700$-chlorophyll $a$-protein 1 with a molecular weight of 110,000 , and highly deficient in three polypeptides with molecular weights of $13,800,15,600$, and 16,500 (Figure 2). In order to correlate the deficiency in these polypeptides with photosynthetic defects, various photosynthetic capacities of viridis- $n^{34}$ and wild-type were determined.

Photosynthetic electron transfer rates were determined either spectrophotometrically or with an oxygen electrode (Table I). The sequential flow of electrons through photosystem II and photosystem I was measured spectrophotometrically with $\mathrm{H}_{2} \mathrm{O}$ as the electron donor and $\mathrm{NADP}^{+}$as the electron acceptor. The rate of

TABLE 1

Photosynthetic electron transport in barley chloroplasts from wild-type and the nuclear gene mutant viridis- $n^{34}$.

\begin{tabular}{|c|c|c|c|c|c|}
\hline $\begin{array}{l}\text { Activity } \\
\text { measured }\end{array}$ & $\begin{array}{c}\text { Electron } \\
\text { donor }\end{array}$ & $\begin{array}{l}\text { Electron } \\
\text { acceptor }\end{array}$ & Additives & Wild-type & viridis $-n^{34}$ \\
\hline $\begin{array}{l}\text { Spectrophoto- } \\
\text { metric } \\
\text { measurements: }\end{array}$ & & & & \multicolumn{2}{|c|}{$\begin{array}{l}\mu \mathrm{moles} \text { of reduced } \\
\text { acceptor } \cdot \mathrm{hr}^{-1} \cdot \mathrm{mg}^{-1} \text { chlorophyll }\end{array}$} \\
\hline PSI + PSII & $\mathrm{H}_{2} \mathrm{O}$ & $\mathrm{FeCN}$ & - & 68 & 17 \\
\hline PSI + PSII & $\mathrm{H}_{2} \mathrm{O}$ & $\mathrm{FeCN}$ & DCMU & 0 & 0 \\
\hline PSI + PSII & $\mathrm{H}_{2} \mathrm{O}$ & $\mathrm{FeCN}$ & GD & 175 & 22 \\
\hline PSI + PSII & $\mathrm{H}_{2} \mathrm{O}$ & $\mathrm{FeCN}$ & GD, DBMIB & 46 & 15 \\
\hline PSII & $\mathrm{H}_{2} \mathrm{O}$ & PD, FeCN & - & 171 & 132 \\
\hline PSII & $\mathrm{H}_{2} \mathrm{O}$ & $\mathrm{PD}, \mathrm{FeCN}$ & DBMIB & 165 & 128 \\
\hline PSI + PSII & $\mathrm{H}_{2} \mathrm{O}$ & NADP + & - & 10 & 0.3 \\
\hline PSI & Asc, DCIP & $\mathrm{NADP}^{+}$ & - & 5 & 0.3 \\
\hline \multicolumn{4}{|l|}{$\begin{array}{l}\text { Oxygen } \\
\text { electrode } \\
\text { measurements: }\end{array}$} & \multicolumn{2}{|c|}{$\begin{array}{c}\mu \text { moles } \mathrm{O}_{2} \\
\text { evolved } \cdot \mathrm{hr}^{-1} \cdot \mathrm{mg}^{-1} \text { chlorophyll }\end{array}$} \\
\hline PSII & $\mathrm{H}_{2} \mathrm{O}$ & $\mathrm{PD}, \mathrm{FeCN}$ & & 71 & 77 \\
\hline PSI & Asc, TMPD & $\mathrm{MeV}$ & & -592 & -66 \\
\hline
\end{tabular}




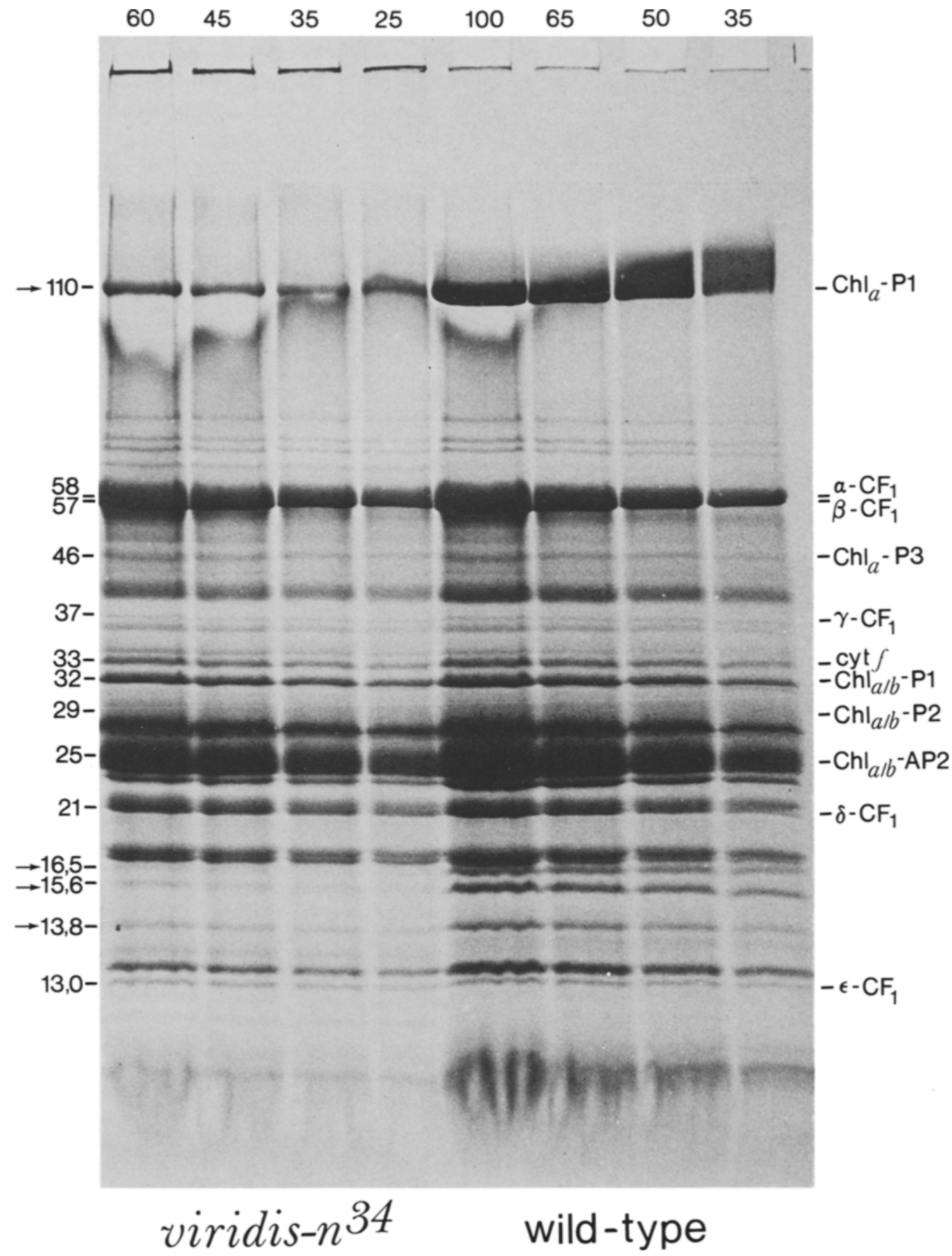

Figure 2. Polypeptide pattern obtained by SDS-PAGE of thylakoids from wild-type barley and the nuclear gene mutant viridis- $n^{34}$.

The separation was carried out by use of an $11-15 \%$ gradient gel and the micrograms of chlorophyll applied are indicated in the respective slots. The polypeptides which were found deficient in the mutant are marked by arrows. The position of the hitherto identified polypeptides in the wild-type pattern is also indicated (22). The nomenclature system used is as defined in (29). 
NADP + reduction was $10 \mu$ moles $\cdot \mathrm{hr}^{-1} \cdot \mathrm{mg}^{-1}$ chlorophyll for wild-type compared with only $0.3 \mu \mathrm{mole} \cdot \mathrm{hr}^{-1} \cdot \mathrm{mg}^{-1}$ chlorophyll for viridis$n^{34}$. Thus for the experimental conditions used, the rate observed for viridis $-n^{34}$ was less than $5 \%$ of the wild-type rate. When the electron acceptor NADP + was replaced by ferricyanide and the photophosphorylation uncoupler gramicidin $\mathrm{D}$ was present, the respective rates observed were 68 and $17 \mu$ moles $\cdot \mathrm{hr}^{-1} \cdot \mathrm{mg}^{-1}$ chlorophyll. Ferricyanide operates mainly as an electron acceptor at or very near the electron carrier X (42) and therefore by-passes electron transfer via ferredoxin and ferredoxin-NADP + oxidoreductase. Because of the loss of ferredoxin and partial loss of the oxidoreductase during preparation of the chloroplasts, this latter part of the electron transfer is severely rate limiting (24, 44). To compensate for these losses, saturating amounts of both proteins were added to the incubation mixtures with NADP + as electron acceptor. However, optimal rates are not necessarily reestablished by this procedure. Ferricyanide can also accept electrons directly from photosystem II when the electron flow through photosystem I is blocked or when broken, sonicated or detergent treated chloroplasts are used $(42,43)$. DBMIB acts as a plastoquinone antagonist and is a potent inhibitor of electron transport between photosystem II and photosystem I $(8,45)$. As expected, the addition of DBMIB to the reaction mixture decreased the rate of ferricyanide reduction by wild-type chloroplasts. However, for viridis $-n^{34}$ the decrease in ferricyanide reduction was barely detectable. The mutant is therefore either defective in photosystem I electron transport or has an altered membrane structure which makes its photosystem II acceptor site accessible to ferricyanide.

Direct measurement of photosystem II electron transfer was carried out with $\mathrm{H}_{2} \mathrm{O}$ as the electron donor and p-phenylenediamine and ferricyanide as electron acceptors. $p$-Phenylenediamine is a lipophilic compound which can partition into the membrane and thereby acts as a shuttle moving reducing equivalents from plastohydroquinone in the membrane to ferricyanide located at the membrane surface $(32$, 46). The rate of photosystem II electron transfer observed with viridis $-n^{34}$ was comparable to the wild-type rate when measured either spectrophotometrically by the rate of ferricyanide photoreduction or by the rate of oxygen evolution (Table I). As expected for photosystem II electron transfer, the rates observed were not sensitive to DBMIB. From these data, photosystem II electron transport in viridis $-n^{34}$ is normal and appears to be catalyzed by polypeptides unrelated to those missing in viridis $-n^{34}$.

In contrast to the results obtained for photosystem II, measurements of photosystem I activity revealed distinct differences between viridis $-n^{34}$ and wild-type. Photosystem I activity was again determined both spectrophotometrically and by use of an oxygen electrode. The level of activity in viridis $-n^{34}$ was found to be less than $10 \%$ of that in wild-type, when NADP + was the electron acceptor and ascorbate plus DCIP the electron donor. It was likewise low in the assay measuring oxygen consumption upon photosystem I mediated methyl viologen reduction. In order to characterize other components of the electron transport chain in the mutant the following measurements were carried out.

Light induced absorbance changes at $518 \mathrm{~nm}$ and photooxidation of cytochrome $f$ were determined in intact leaves of the wild-type and viridis $-n^{34}$. The absorption change at $518 \mathrm{~nm}$ was measured during irradiation of the leaves with a broad band of red light or red light filtered through either a $710 \mathrm{~nm}$ or a $641 \mathrm{~nm}$ interference filter (Figure 3). The $518 \mathrm{~nm}$ absorbance change is usually composed of two distinct phases (26). The rapid change, frequently seen as a spike in kinetic measurements, indicates the formation of a membrane potential in or across the thylakoid membrane. The subsequent slow change is associated with lightdependent energization of the thylakoid membrane and establishment of a proton gradient across the membrane $(26,41)$. Both wild-type and viridis $-n^{34}$ leaves showed the fast component of the $518 \mathrm{~nm}$ change. This is best seen in the low intensity irradiations where narrow-band interference filters were used (Figure $3 \mathrm{~b}$ and $\mathrm{c}$ ). The slow component, which is dependent upon electrons generated by photosystem II, was indeed absent in wild-type and viridis $-n^{34}$ seedlings irradiated with far-red light that preferentially excites photosystem I. Irradiation with red light or red light passed through the $641 \mathrm{~nm}$ 

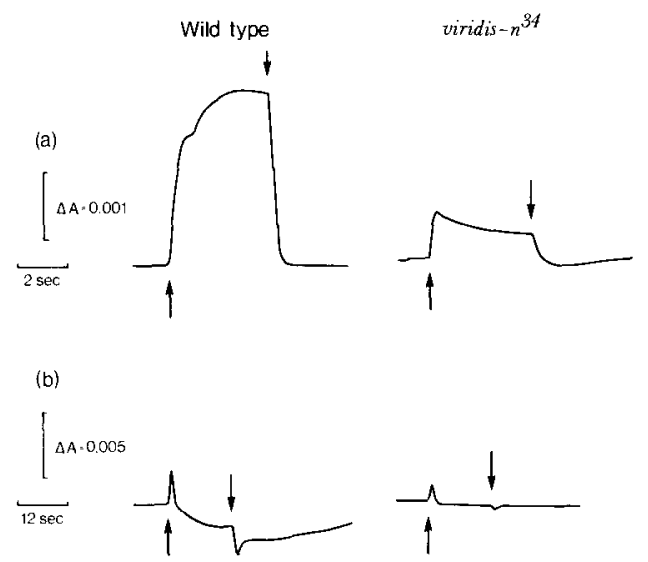

(c)

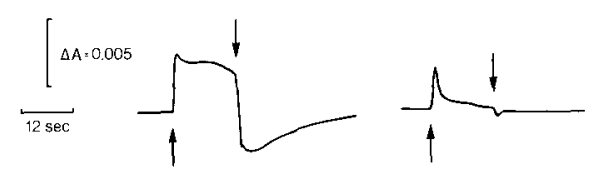

Figure 3. Light dependent absorbance change at 518 $\mathrm{nm}$ in leaf segments of wild-type barley and viridis$n^{34}$.

The leaves were illuminated with red light (a), light at $710 \mathrm{~nm}$ (b), or light at $641 \mathrm{~nm}$ (c). Upward arrow, light on; downward arrow, light off.

interference filter resulted in a slow $518 \mathrm{~nm}$ absorbance change. This change was however greatly reduced in viridis- $n^{34}$ indicating a restricted flow of electrons between the two photosystems.

Photooxidation of cytochrome $f$ in the intact leaf was measured as a decrease in absorbance at $554 \mathrm{~nm}(34,39)$. Cytochrome $f$ is situated between the two photosystems. It is oxidized by photosystem I in the light and reduced in the dark period by reductants generated via photosystem II during the period of illumination. Upon excitation of both photosystems with a broad band of red light, the extent of photooxidation of cytochrome $f$ was low in viridis $-n^{34}$ compared with wild-type (Figure 4a). Preferential excitation of photosystem II by use of red light of wave-lengths around $641 \mathrm{~nm}$ (Figure 4c) produces cytochrome $f$ absorbance changes similar to those observed with broad band illumination, except that a prolonged irradiation was required for maximum photooxidation of cytochrome $f$ in the wild-type.
A more significant difference was observed by using far-red light which preferentially excites photosystem I (Figure 4b). Under these conditions, the absorbance decrease observed in viridis $-n^{34}$ upon illumination was only $7 \%$ of the change observed in wild-type. This indicates that the mutant is deficient either in cytochrome $f$ or in photosystem I mediated oxidation of cytochrome $f$. The rate of dark-reduction of cytochrome $f$ following irradiation with $710 \mathrm{~nm}$ light was faster in viridis- $n^{34}\left(\mathrm{t}_{1 / 2}=0.5 \mathrm{~s}\right)$ than in wild-type $\left(t_{1} / 2=18.6 \mathrm{~s}\right)$, supporting the notion that the ratio of photosystem II to photosystem I activity is high in viridis $-n^{34}$ compared with wild-type.

To further localize the observed defect of electron transfer in viridis $-n^{34}$, the cytochrome levels in mutant and wild-type chloroplasts were determined from their reduced minus oxidized difference spectra (15). On a chlorophyll basis, the measured levels of cytochromes $f, b_{6}$, and $b_{559}$ (Table II) were found to be slightly increased in viridis- $n^{34}$ compared with wild-type and the low photosystem I activity observed in viridis$n^{34}$ is thus not due to the lack of a cytochrometype electron carrier. Because of the low light

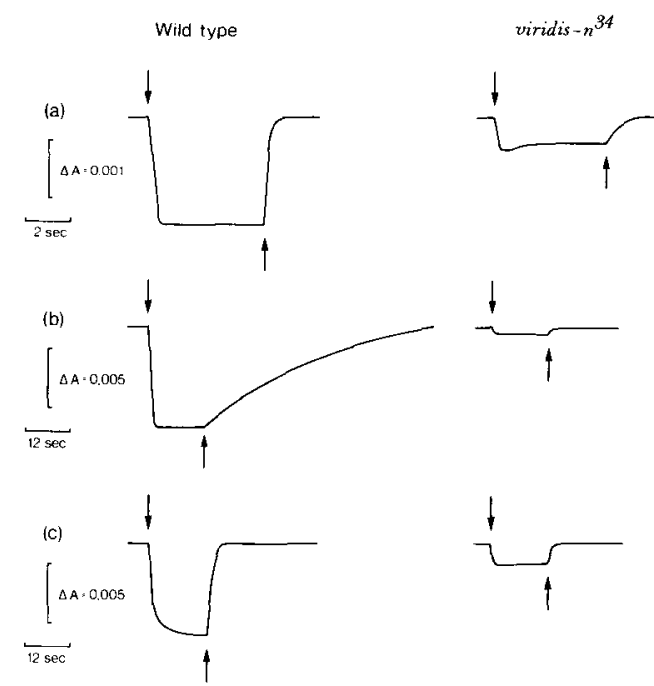

Figure 4. Photooxidation and dark reduction of cytochrome $f$ in leaf segments of wild-type barley and the nuclear gene mutant viridis $-n^{34}$.

The leaves were illuminated with red light (a), light at $710 \mathrm{~nm}$ (b), and light at $641 \mathrm{~nm}$ (c). Downward arrow, light on; upward arrow, light off. 
Cytochrome content of barley chloroplasts from wild-type and the nuclear gene mutant viridis $-n^{34}$.

\begin{tabular}{cccc}
\hline & & Molar ratio & \\
Plant material & Chl/Cyt $f$ & Chl/Cyt $b_{6}$ & Chl/Cyt $b_{559}$ \\
\cline { 2 - 4 } & 1780 & 500 & 890 \\
wild-type & 1640 & 350 & 650 \\
viridis-n $n^{34}$ & & \\
\hline
\end{tabular}

intensity at which the plants were grown, the ratios of chlorophyll to cytochromes are high as is typical for shade conditions $(6,34)$. The presence of cytochrome $f$ in viridis- $n^{34}$ was also indicated from the electrophoretic pattern (Figure 2).

The SDS-PAGE polypeptide pattern of viridis- $n^{34}$ compared to wild-type revealed a diminished content of chlorophyll $a$-protein 1 in the mutant thylakoids. Because this polypeptide is thought to carry the reaction centre P700 of photosystem I and because the viridis $-n^{34}$ thylakoids were deficient in photosystem I activity, it was of interest to examine viridis $-n^{34}$ for $P 700$. For wild-type thylakoids the oxidized minus reduced absorption spectrum showed the expected minimum at $696 \mathrm{~nm}$, but only a slight shoulder could be detected at $696 \mathrm{~nm}$ for viridis$n^{34}$ thylakoids. From the difference spectra, the chlorophyll $/ P 700$ ratio was calculated to be 240 for wild-type and greater than 10,000 for viridis$n^{34}$. Thus the reaction centre of photosystem $I$ is highly impaired in viridis $-n^{34}$. Due to the difficulties in differentiating viridis $-n^{34}$ seedlings from the wild-type phenotype, contamination with wild-type leaves may be responsible for the $P 700$ activity detected in viridis $-n^{34}$.

One predictable consequence of the impairment of the photosystem I reaction centre in viridis $-n^{34}$ to mediate electron transfer would be a decrease in the ability of mutant thylakoids to generate a light dependent proton gradient. Under conditions where wild-type thylakoids generated a proton gradient of $0.3 \mu$ mole $\cdot \mathrm{mg}^{-1}$ chlorophyll, thylakoids of viridis $-n^{34}$ produced a barely detectable gradient (Figure 5).

Further characterization of viridis- $n^{34}$ with respect to photosynthetic capacity was carried out by activity measurements of ferredoxinNADP ${ }^{+}$oxidoreductase. The amount of ferre-

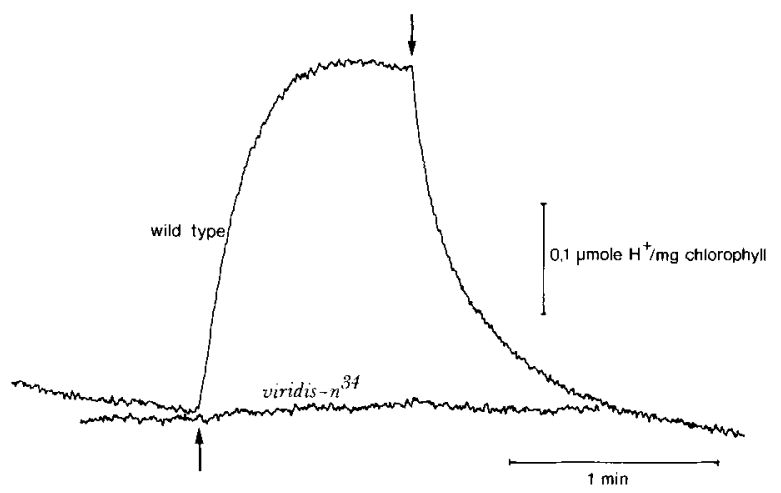

Figure 5. Light induced changes in the $\mathrm{pH}$ of the medium containing chloroplasts of wild-type barley or viridis $-n^{34}$. Upward arrow, light on; downward arrow, light off.

doxin-NADP + oxidoreductase present in wildtype chloroplasts was able to reduce $11.6 \mu$ moles DCIP $\cdot \mathrm{hr}^{-1} \cdot \mathrm{mg}^{-1}$ chlorophyll while the amount found in viridis $-n^{34}$ was able to reduce 16.1 $\mu$ moles DCIP $\cdot \mathrm{hr}^{-1} \cdot \mathrm{mg}^{-1}$ chlorophyll. These activities are comparable and indicate that the mutant does not differ from wild-type with respect to this protein.

\section{DISCUSSION}

In higher plants, only a few mutants have been described as defective in photosystem I. The plastome mutant en:alba-1 from Antirrhinum majus lacks chlorophyll $a$-protein 1 and probably its apoprotein under conditions permitting partial greening of the plastids (17). In comparison to wild-type, the plastids showed an approximately $50 \%$ reduction per chlorophyll in Hill activity with either DCIP or ferricyanide as 
electron acceptor (18). Measurements which specifically pinpoint the defect to photosystem I have however not been provided. The plastome mutant en:gil- 1 of Pelargonium zonale lacks chlorophyll $a$-protein 1 and its apoprotein (20). The leaves gave a delayed light emission signal comparable to that of wild-type, but were deficient in an electron spin resonance signal observable in wild-type leaves (19). In the absence of photochemical measurements it cannot be decided whether this mutant has a specific lesion in photosystem $\mathrm{I}$.

The two barley mutants viridis $-k^{23}$ and xantha- $l^{35}$ have erroneously been cited as photosystem I mutants in (30). It has been shown that these mutants contain photosystem I and II activities and maintain a proton gradient upon illumination $(16,33)$.

In corn two groups of photosystem I deficient mutants have been described $(30,31)$. An analysis of chlorophyll containing proteins revealed one group to be deficient in chlorophyll $a$ protein 1 . Of the five mutants in this group, one (hcf 1489B) was lacking P700 activity, had only $10 \%$ of the wild-type level of photosystem I activity (DCIP to MeV) and substantial photosystem II activity as measured by DBMIB reduction. This mutant may be similar to viridis$n^{34}$ in barley and it will be of interest to see if it lacks the low molecular weight polypeptides characteristic for photosystem I and whether SDS-PAGE reveals a partial or complete absence of the 110,000 molecular weight band. Among the other four mutants in the group, one had small amounts of chlorophyll a-protein 1 and significant photosystem I activity, whereas the remaining three were impaired in both photosystems. The second group of photosystem I deficient mutants in corn (31) were complex lesions characterized, inter alia, by the additional absence of chlorophyll $a / b$ proteins.

While a deficient function of photosystem I can be recognized by photochemical measurements or by fluorescence induction kinetics, this does not necessarily mean that the primary lesion resides in photosystem I. Likewise, the absence or reduction of chlorophyll $a$-protein 1 per se is not sufficient to designate a mutant as a photosystem I mutant.

In Chlamydomonas four mutants have been analyzed which lack $P 700$ and photosystem I activity but contain the other tested components of the electron transport chain. Three of these (ac-80, Fl and F14) are nuclear gene mutants lacking chlorophyll $a$-protein $1(12,14)$. The fourth mutant $\left(C_{1}\right)$ displays non-mendelian inheritance and is highly deficient in chlorophyll a-protein 1 (5).

Employing inhibitors of protein synthesis on cytoplasmic and chloroplastic ribosomes in conjunction with mutants resistant towards these inhibitors, Chua and Gillham (11) have shown that the presence of chlorophyll $a$-protein 1 in the Chlamydomonas thylakoid membrane is dependent on protein synthesis in both the cytoplasmic and chloroplastic compartments. Whether or not this implies that chlorophyll $a$ protein 1 is made up of one chloroplast coded and one nuclear coded polypeptide is presently not known. The residual chlorophyll protein at the position of chlorophyll $a$-protein 1 of the nuclear mutant viridis- $n^{34}$ in barley could represent a chloroplast coded polypeptide. In such a case both polypeptides are required for the establishment of an active $P 700$ reaction centre.

In addition to the deficiency in the chlorophyll $a$-protein 1 , mutant viridis $-n^{34}$ is highly deficient in three polypeptides of lower molecular weights, namely $13,800,15,600$, and 16,500. Isolated photosystem I particles from the wildtype $(37,48)$ contained $110,000,16,500$, and 15,600 molecular weight polypeptides corresponding to three of the polypeptides deficient in viridis $-n^{34}$ and an additional three polepeptides $(33,000,32,500,13,800)$ which are present in comparable particles of viridis- $n^{34}$ (to be described in a subsequent publication).

Photosystem I particles composed of six components have earlier been reported isolated from Swiss chard leaves $(3,4)$ and the function of these polypeptides has tentatively been identified as follows. The particle contains two polypeptides with a molecular weight of 110,000 and these carry the antenna chlorophylls which transfer energy to the $P 700$ reaction centre located on one of these polypeptides. A polypeptide with a molecular weight of 20,000 is suggested involved in the binding of plastocyanin. Three polypeptides with molecular weights of $18,000,16,000$, and 8,000 were suggested to be iron-sulfur proteins mediating the transfer of electrons from the primary acceptor on the 
110,000 molecular weight polypeptide to soluble ferredoxin (4). Recently, an additional ironsulfur protein has been shown involved in this electron transfer (35). Iron-sulfur proteins are likely candidates for the three small polypeptides present in minute amounts in viridis $-n^{34}$. The fourth iron-sulfur protein with a molecular weight of 8,000 may also be missing in the mutant. Low resolution in this molecular weight range of our gels does not permit a decision on this point. The presence or absence of these ironsulfur proteins in the mutant will be investigated directly by electron spin resonance spectroscopy (40).

The absence or near absence of $P 700$ in viridis $-n^{34}$ as judged from its chemically oxidized minus reduced spectrum can explain all the photochemical results obtained with this mutant. The absence of a functional $P 700$ reaction centre may also prevent the incorporation of the ironsulfur proteins into the membrane. Alternatively, the absence of iron-sulfur proteins may prevent the formation of a $P 700$ reaction centre detectable by difference spectroscopy.

\section{ACKNOWLEDGEMENTS}

We gratefully thank Professor D. vON WETTSTEIN for a critical review of the manuscript. Dr. C. Gamini Kannangara is thanked for providing purified ferredoxin-NADP + oxidoreductase. Susanne Placing, Ann-Sofi Steinholtz, Nina Rasmussen, and Hanne Them Nielsen are thanked for skillful technical assistance. Financial support was provided by EEC Contract 029-76-ES-DK Solar Energy Programme to Professor D. von WeTtSTEIN.

\section{REFERENCES}

1. Arnon, D. I: Copper enzymes in isolated chloroplasts. Polyphenoloxidase in Beta vulgaris. Plant Physiol. 24, 1-14 (1949)

2. Bendall, D. S., H. E. Davenport \& R. Hill: Cytochrome components in chloroplasts of the higher plants. In: Methods Enzymol. (A. San Pietro, ed.) Academic Press, New York and London 23, 327-344 (1971)

3. Bengis, C. \& N. Nelson: Purification and properties of the photosystem I reaction center from chloroplasts. J. Biol. Chem. 250, 27832788 (1975)
4. Bengis, C. \& N. Nelson: Subunit structure of chloroplast photosystem I reaction center. J. Biol. Chem. 252, 4564-4569 (1977)

5. Bennoun, P., J. Girard \& N.-H. Chua: A uniparental mutant of Chlamydomonas reinhardtii deficient in the chlorophyll-protein complex CPI. Molec. gen. Genet. 153, 343-348 (1977)

6. Boardman, N. K.: Comparative photosynthesis of sun and shade plants. Ann. Rev. Plant Physiol. 28, 355-377 (1977)

7. Buchanan, B. B. \& D. I. Arnon: Ferredoxins from photosynthetic bacteria, algae, and higher plants. In: Methods Enzymol. (A. San Pietro, ed.) Academic Press, New York and London 23 413-440 (1971)

8. Böhme, H., S. Reimer \& A. Trebst: The effect of dibromothymoquinone, an antagonist of plastoquinone, on non-cyclic and cyclic electron flow systems in isolated chloroplasts. Z. Naturforsch. 26b, 341-352 (1971)

9. Chow, W. S. \& A. B. Hope: Proton translocation, electron transport and photophosphorylation in isolated chloroplasts. Aust. J. Plant Physiol. 4, 647-665 (1977)

10. Chua, N.-H. \& P. Bennoun: Thylakoid membrane polypeptides of Chlamydomonas reinhardtii: Wild type and mutant strains deficient in photosystem II reaction center. Proc. Nat. Acad. Sci. USA 72, 2175-2179 (1975)

11. Chua, N.-H. \& N. W. Gillmam: The sites of synthesis of the principal thylakoid membrane polypeptides in Chlamydomonas reinhardtii: $\mathrm{J}$. Cell Biol. 74, 441-452 (1977)

12. Chua, N.-H., K. Matlin \& P. Bennoun: A chlorophyll-protein complex lacking in photosystem I mutants of Chlamydomonas reinhardtii: J. Cell Biol. 67, 361-377 (1975)

13. Fork, D. C. \& U. W. Heber: Studies on electron-transport reactions of photosynthesis in plastome mutants of Oenothera. Plant Physiol. $43,606-612$ (1968)

14. Givan, A. L. \& R. P. Levine: The photosynthetic electron transport chain of Chlamydomonas reinhardi. VII. Photosynthetic phosphorylation by a mutant strain of Chlamydomonas reinhardi deficient in active P700. Plant Physiol. 42, 1264-1268 (1967)

15. Henningsen, K. W. \& N. K. Boardman: Development of photochemical activity and the appearance of the high potential form of cytochrome $b-559$ in greening barley seedlings. Plant Physiol. 51, 1117-1126 (1973)

16. Henningsen, K. W., N. C. Nielsen \& R. M. SMILLIE: The effect of nuclear mutations on the assembly of photosynthetic membranes in barley. Port. Acta Biol. Ser. A 14, 323-344 (1974) 
17. Herrmann, F.: Genetic control of pigmentprotein complexes I and Ia of the plastid mutant en:alba-1 of Antirrhinum majus. FEBS Lett. 19 , 267-269 (1971)

18. Herrmann, F.: Struktur und Funktion der genetischen Information in den Plastiden. II. Untersuchung der photosynthesedefekten Plastommutante alba-1 von Antirrhinum majus L. Photosynthetica 5, 258-266 (1971)

19. Herrmann, F., D. Matorin, K. Timofeev, T. BöRnER, A. B. Rubin \& R. Hagemann: Structure and function of the genetic information in plastids. IX. Studies on primary reactions of photosynthesis in plastom mutants of Antirrhinum majus and Pelargonium zonale having impaired photosynthesis. Biochem. Physiol. Pflanzen 165, 393-400 (1974)

20. Herrmann, F. H., B. Schumann, T. Börner \& R. KNoth: Structur und Funktion der genetischen Information in den Plastiden. XII. Die plastidalen Lamellarproteine der photosynthesedefekten Plastommutante en:gil-1 ( $($ Mrs. Pollock «) und der Genmutante »Cloth of Gold» von Pelargonium zonale Ait. Photosynthetica 10 , 164-171 (1976)

21. Hiyama, T. \& B. Ke: Difference spectra and extinction coefficients of P700. Biochim. Biophys. Acta 267, 160-171 (1972)

22. Høyer-Hansen, G., B. L. Møller \& L. C. Pan: Identification of coupling factor subunits in thylakoid polypeptide patterns of wild-type and mutant barley thylakoids using crossed immunoelectrophoresis. Carlsberg Res. Commun. 44. 337-351 (1979)

23. Høyer-Hansen, G. \& D. J. Simpson: Changes in the polypeptide composition of internal membranes of barley plastids during greening. Carlsberg Res. Commun. 42, 379-389 (1977)

24. Izawa, S., T. N. Connolly, G. D. Winget \& N. E. Good: Inhibition and uncoupling of photophosphorylation in chloroplasts. Brookhaven Symp. Biology 19, 169-187 (1967)

25. Катон, S.: Plastocyanin. In: Methods Enzymol. (A. San Pietro, ed.) Academic Press, New York and London 23, 408-413 (1971)

26. Larkum, A. W. D. \& W. D. Bonner: Lightinduced absorbance changes of P518 in intact plastids. Biochim. Biophys. Acta 256, 396-408 (1972)

27. Lowry, O. H., N. J. Rosebrough, A. L. Farr \& R. J. Randall: Protein measurement with the Folin phenol reagent. J. Biol. Chem. 193, 265275 (1951)

28. Machold, O. \& G. Høyer-Hansen: Polypeptide composition of thylakoids from viridis and xantha mutants in barley. Carlsberg Res. Commun. 41, 359-366 (1976)

29. Machold, O., D. J. Simpson \& B. L. Møller: Chlorophyll-proteins of thylakoids from wildtype and mutants of barley (Hordeum vulgare L.). Carlsberg Res. Commun. 44, 235-254 (1979)

30. Miles, D.: Mutants of higher plants: Maize. In: Methods Enzymol. (A. San Pietro, ed.) Academic Press, New York and London 69, 3-23 (1979)

31. Miles, C. D., J. P. Markwell \& J. P. THORNBER: The effect of nuclear mutation in maize on photosynthetic activity and content of chlorophyll-protein complexes. Plant Physiol. 64, 690-694 (1979)

32. Nielsen, N. C. \& R. M. Smilue: The effect of $p$ phenylenediamine and dibromothymoquinone on the photosynthetic electron transport and proton pump activities of isolated barley chloroplasts. Arch. Biochem. Biophys. 186, 52-59 (1978)

33. Nielsen, N. C., R. M. Smillie, K. W. HenningSEN, D. von WetTSTein \& C. S. French Composition and function of thylakoid membranes from grana-rich and grana-deficient chloroplast mutants of barley. Plant Physiol. 63, 174182 (1979)

34. RüHLE, W. \& A. WILD: Measurements of cytochrome $f$ and P-700 in intact leaves of Sinapis alba grown under high-light and lowlight conditions. Planta 146, 377-385 (1979)

35. Sauer, K., P. Mathis, S. Acker \& J. A. van BEST: Electron acceptors associated with $P-700$ in triton solubilized photosystem I particles from spinach chloroplasts. Biochim. Biophys. Acta 503, 120-134 (1978)

36. Simpson, D., G. Høyer-Hansen, N.-H. Chua \& D. vON WETTSTEIN: The use of gene mutants in barley to correlate thylakoid polypeptide composition with the structure of the photosynthetic membrane. Proc. Int. Congr. Photosynth., 4th (D. O. Hall, J. Coombs \& T. W. Goodwin, eds.) Biochemical Society, England pp. 537-548 (1977)

37. Simpson, D., B. L. Møller \& G. HøyerHANSEN: Freeze-fracture structure and polypep. tide composition of thylakoids of wild-type and mutant barley plastids. In: Chloroplast Development (G. Akoyunoglou \& J. H. ArgyroudiAkoyunoglou, eds.) Elsevier/North-Holland, Biomedical Press, Amsterdam pp. 507-512 (1978)

38. Smillie, R. M., N. C. Niflsen, K. W. HenningSEN \& D. vON WetTSTEIN: Development of 
photochemical activity in chloroplast membranes. I. Studies with mutants of barley grown under a single environment. Aust. J. Plant Physiol. 4, 415-438 (1977)

39. Smillie, R. M. \& R. Nott: Assay of chilling injury in wild and domestic tomatoes based on photosystem activity of the chilled leaves. Plant Physiol. 63, 796-801 (1979)

40. Telfer, A., J. Barber, P. Heathcote \& M. C. W. Evans: Variable chlorophyll a fluorescence from $P-700$ enriched photosystem I particles dependent on the redox state of the reaction centre. Biochim. Biophys. Acta 504, 153-164 (1978)

41. Thorne, S. W., G. Horvath, A. Kahn \& N. K. BOARDMAN: Light-dependent absorption and selective scattering changes at $518 \mathrm{~nm}$ in chloroplast thylakoid membranes. Proc. Nat. Acad. Sci. USA 72, 3858-3862 (1975)

42. Trebst, A.: On the role of plastoquinone and on the nature of the primary acceptor of photosystem I in photosynthetic electron transport of chloroplasts. In: Proc. Int. Congr. Photosynth. Res., 2nd. The Hague, Neth. 1, 399-417 (1971)

43. Trebst, A.: Measurement of Hill reactions and photoreduction. In: Methods Enzymol. (A. San Pietro, ed.) Academic Press, New York and London 24, 146-164 (1972)
44. TREBST, A.: Energy conservation in photosynthetic electron transport of chloroplasts. Ann. Rev. Plant. Physiol. 25, 423-458 (1974)

45. Trebst, A., E. Harth \& W. Draber: On a new inhibitor of photosynthetic electron-transport in isolated chloroplasts. Z. Naturforsch. 25b, 1157-1159 (1970)

46. Trebst, A. \& S. Reimer: Energy conservation in photoreductions by photosystem II. Reversal of dibromothymoquinone inhibition of Hill reactions of phenylenediamines. Z. Naturforsch. $28 \mathrm{c}$ 710-716 (1973)

47. Wetrstein, D. von \& K. Kristiansen: Stock list for nuclear gene mutants affecting the chloroplast. Barley Genet. Newslett. 3, 113-117(1973)

48. Wettstein, D. von, B. L. Møller, G. HøyerHansen \& D. Simpson: Genetic manipulation of photosystem I and II in chloroplast membranes. In: Proceedings 2nd. Coordination Meeting of Contractors EC Solar Energy R \& D Programme, Commission of the European Communities. No. 3560 EN, III/9, pp. 1-9 (1978)

49. Wettstein, D. von, B. L. Møller, G. HøyerHansen \& D. SimPSON: Mutants in the analysis of the photosynthetic membrane polypeptides. In: Origin of chloroplasts. (J. A. Schiff \& R. Y. Stanier, eds.) Elsevier/North-Holland, Biomedical Press, Amsterdam, in press (1980) 